Table 1. Primary outcome and events at 10 years: univariate analysis

\begin{tabular}{lcccc}
\hline & Total study population ( $\mathrm{n}=608)$ & Without GC & With CG & P Value \\
\hline Primary outcome & $95(15.6 \%)$ & $24(11.4 \%)$ & $71(17.9 \%)$ & 0.035 \\
Death & $10(1.6 \%)$ & $1(0.5 \%)$ & $9(2.3 \%)$ & 0.103 \\
Cardiovascular diseases & $18(3 \%)$ & $3(1.4 \%)$ & $15(3.8 \%)$ & 0.177 \\
Severe infections & $35(5.8 \%)$ & $5(2.4 \%)$ & $30(7.6 \%)$ & 0.009 \\
Fractures & $32(5.3 \%)$ & $15(7.1 \%)$ & $17(4.3 \%)$ & 0.137 \\
\hline
\end{tabular}

Table 2. Time-dependent relationship between glucocorticoids treatment and risk of events estimated by hazard ratio

\begin{tabular}{lc}
\hline Time (Months) & Hazard Ratio $(95 \% \mathrm{Cl})$ \\
\hline 12 & $0.46(0.23-0.90)$ \\
24 & $0.62(0.36-1.08)$ \\
36 & $0.83(0.52-1.33)$ \\
48 & $1.12(0.73-1.72)$ \\
60 & $1.52(0.96-2.40)$ \\
72 & $2.05(1.19-3.52)$ \\
84 & $2.77(1.44-5.34)$ \\
96 & $3.74(1.69-8.26)$ \\
108 & $5.05(1.98-12.91)$ \\
\hline
\end{tabular}

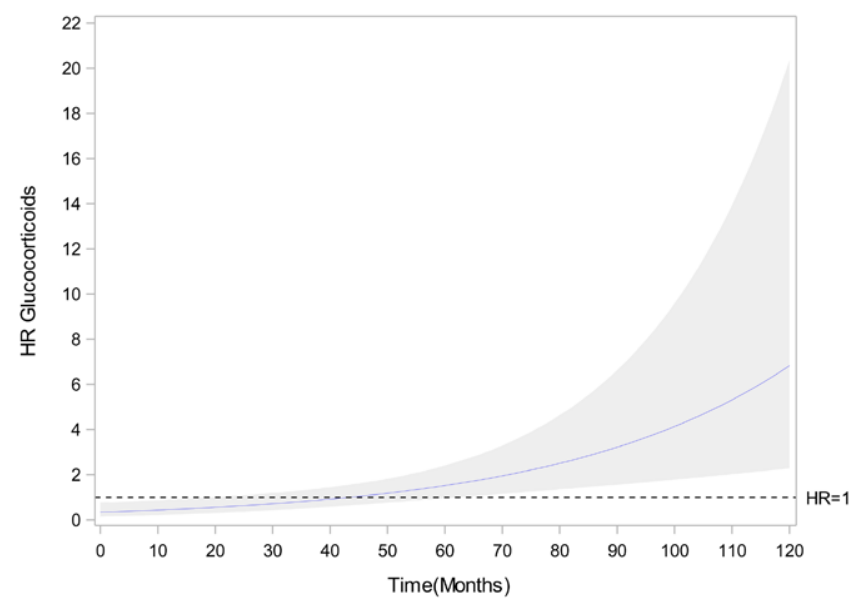

Figure 1. Time-dependent relationship between glucocorticoids treatment and risk of events estimated by hazard ratio (HR)

Conclusion: This 10-year analysis of the ESPOIR cohort supports a dose and time-dependent impact of very low-dose GC treatment in early RA, with a longterm high risk of severe outcomes.

Disclosure of Interests: Camille Roubille Consultant of: Servier, Pfizer, Novartis, Amandine Coffy: None declared, Nathalie Rincheval: None declared, Maxime Dougados Grant/research support from: AbbVie, Eli Lilly, Merck, Novartis, Pfizer and UCB Pharma, Consultant of: AbbVie, Eli Lilly, Merck, Novartis, Pfizer and UCB Pharma, Speakers bureau: AbbVie, Eli Lilly, Merck, Novartis, Pfizer and UCB Pharma, Rene-Marc Flipo Speakers bureau: Novartis, Janssen, Lilly, JeanPierre Daures: None declared, Bernard Combe Grant/research support from: Novartis, Pfizer, Roche-Chugai, Consultant of: AbbVie; Gilead Sciences, Inc.; Janssen; Eli Lilly and Company; Pfizer; Roche-Chugai; Sanofi, Speakers bureau: Bristol-Myers Squibb; Gilead Sciences, Inc.; Eli Lilly and Company; Merck Sharp \& Dohme; Pfizer; Roche-Chugai; UCB

DOI: 10.1136/annrheumdis-2020-eular.3917

\section{OP0117 LONGITUDINAL CHANGE IN THE CENTRAL NERVOUS SYSTEM PAIN RESPONSE AFTER TREATMENT WITH CERTOLIZUMAB OR PLACEBO. A POST-HOC ANALYSIS FROM THE PRECEPRA TRIAL}

J. Rech ${ }^{1}$, K. Tascilar ${ }^{1}$, H. Schenker ${ }^{1}$, M. Hagen ${ }^{1}$, M. Sergeeva ${ }^{2}$ M. Selvakumar ${ }^{2}$, L. Konerth ${ }^{2}$, J. Prade $^{2}$, S. Strobelt ${ }^{2}$, V. Schönau ${ }^{1}$, L. Valor ${ }^{1}$, A. Hueber ${ }^{3}$, D. Simon ${ }^{1}$, A. Kleyer ${ }^{1}$, F. Behrens ${ }^{4}$, C. Baerwald ${ }^{5}$, S. Finzel ${ }^{6}$, R. Voll ${ }^{6}$, E. Feist ${ }^{7}$, J. A. P. Da Silva ${ }^{8}$, A. Doerfler ${ }^{9}$, N. Damjanov ${ }^{10}$, A. Hess ${ }^{2}$, G. Schett ${ }^{1} .{ }^{1}$ Friedrich-Alexander University (FAU) Erlangen-Nürnberg and Universitätsklinikum Erlangen, Department of Internal Medicine 3 Rheumatology and Immunology, Erlangen, Germany; ${ }^{2}$ Friedrich-Alexander University (FAU) Erlangen-Nürnberg, Institute for Experimental Pharmacology,
Erlangen, Germany; ${ }^{3}$ Sozialstiftung Bamberg, Section Rheumatology, Bamberg, Germany; ${ }^{4}$ Goethe University Frankfurt, Rheumatology and Fraunhofer TMP Frankfurt, Germany; ${ }^{5}$ Universitätsklinikum Leipzig, Medizinische Klinik III Bereich Rheumatologie, Leipzig, Germany; ${ }^{6}$ Universitätsklinikum Freiburg, Klinik für Rheumatologie und Klinische Immunologie, Freiburg, Germany; ${ }^{7}$ Klinik für Rheumatologie der Helios Fachklinik, Vogelsang-Gommern, Germany; ${ }^{8}$ Hospitais da Universidade (SRHUC), Department Reumatologia, Coimbra, Portugal; ${ }^{9}$ Friedrich-Alexander-University Erlangen-Nürnberg ( $F A U)$, Universitätsklinikum Erlangen, Abteilung für Neuroradiologie, Erlangen, Germany; ${ }^{10}$ Belgrade University School of Medicine, Institute of Rheumatology, Belgrade, Serbia

Background: Tumor necrosis factor inhibitors have revolutionized the treatment of rheumatoid arthritis (RA). However, only about $50 \%$ of the patients respond well to TNF inhibitors. Therefore, markers that predict response to TNF inhibitors are valuable. Previously we demonstrated that central nervous system (CNS) response to nociceptive stimuli, measured by $\mathrm{fMRI}$ of the brain as blood oxygen level dependent (BOLD) signals, decreases already after 24 hours of anti-TNF administration a higher pre-treatment BOLD signal volume seems to predict clinical response to treatment with certolizumabpegol (CZP) ${ }^{1,2}$. We therefore hypothesized that the baseline volume of BOLD signal in the CNS could predict anti-TNF treatment response.

Objectives: To perform a randomized placebo controlled trial in active RA patients to test the effect of TNF inhibition on arthritis induced pain activ ity in the brain and to test whether patients with high-level RA-related brain activation react differently to TNF-inhibitors than patients with low-level brain activation.

Methods: Adult RA patients fulfilling the 2010 ACR/EULAR classification criteria with a DAS28 $>3.2$ receiving stable DMARD treatment for at least 3 months were eligible. Patients underwent the first $\mathrm{FMRI}$ at screening measuring BOLD signal upon MCP joint compression and were stratified into low ( $<700$ units) and high (>700 units) voxel counts. Then patients were randomized to CZP or placebo with a 2:1 ratio. The second and third fMRI were performed after 12 and 24 weeks, respectively. Control stimulation was done by measuring brain activation after non-painful finger tapping.

Results: 156 RA patients with moderate-to-high disease activity participated in the study. In the finger tapping control, fMRI showed no significant changes in BOLD signal in the CZP-L and CZP-H arms, but a slight but significant decrease $(p=0.043)$ was observed. After joint compression, the CZP-L group showed significant increase in the BOLD signal volume $(p=0.043)$ in $\mathrm{fMRI}-2$ as compared to fMRI-1 with no further significant changes. In contrast, in the CZP-H group, the BOLD signal volume significantly decreased $(p=0.037)$ in $\mathrm{fMRI}-2$ and continued
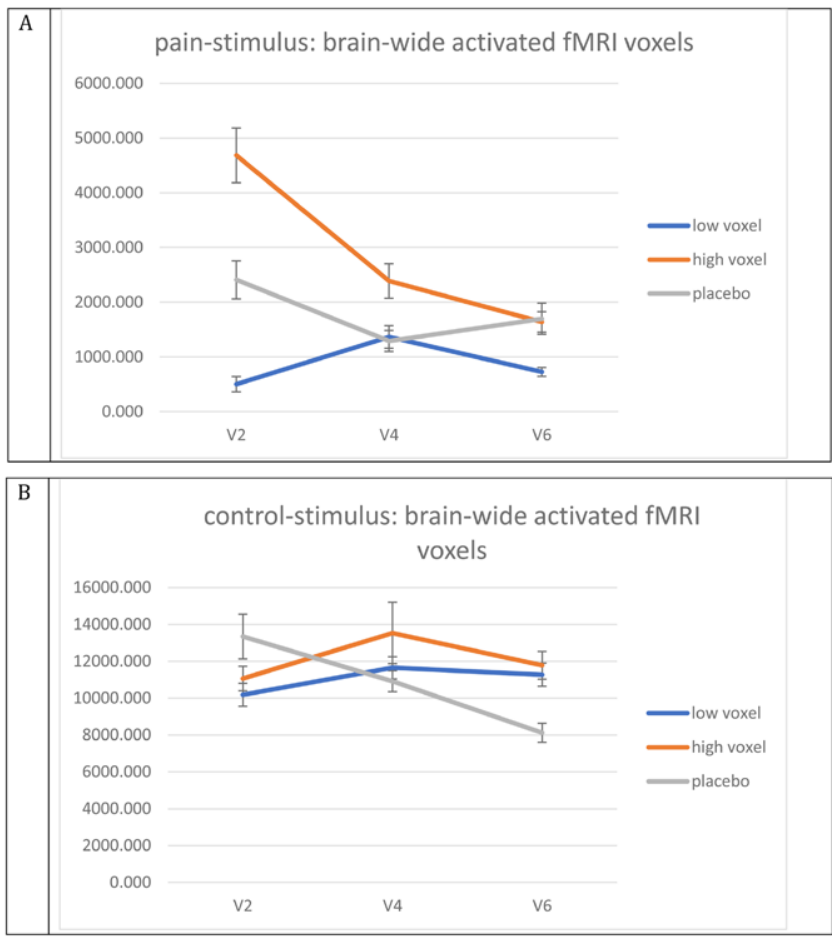

Fig 1. BOLD fMRI responses to painful stimulation 
to decrease further, $p=0.007$. No significant changes were observed in the placebo arm over time.

Conclusion: TNF inhibition improves arthritis-related brain activity in the subgroup of RA patients with high baseline BOLD activity in the fMRI.

References:

[1] Hess, A et al. PNAS (2011).

[2] Rech, J. et al. Arthritis \& Rheumatism (2013).

Acknowledgments: The study was supported by an unrestricted grant of UCB Biopharma SPRL Brussels, Belgium

Disclosure of Interests: Jürgen Rech Consultant of: BMS, Celgene, Novartis, Roche, Chugai, Speakers bureau: AbbVie, Biogen, BMS, Celgene, MSD, Novartis, Roche, Chugai, Pfizer, Lilly, Koray Tascilar: None declared, Hannah Schenker: None declared, Melanie Hagen: None declared, Marina Sergeeva: None declared, Mageshwar Selvakumar: None declared, Laura Konerth: None declared, Jutta Prade: None declared, Sandra Strobelt: None declared, Verena Schönau: None declared, Larissa Valor: None declared, Axel Hueber Grant/ research support from: Novartis, Lilly, Pfizer, EIT Health, EU-IMI, DFG, Universität Erlangen (EFI), Consultant of: Abbvie, BMS, Celgene, Gilead, GSK, Lilly, Novartis, Speakers bureau: GSK, Lilly, Novartis, David Simon Grant/ research support from: Else Kröner-Memorial Scholarship, Novartis, Consultant of: Novartis, Lilly, Arnd Kleyer Consultant of: Lilly, Gilead, Novartis, Abbvie, Speakers bureau: Novartis, Lilly, Frank Behrens Grant/research support from: Abbvie, Pfizer, Roche, Chugai, Janssen, Consultant of: Abbvie, Pfizer, Roche, Chugai, UCB, BMS, Celgene, MSD, Novartis, Biotest, Janssen, Genzyme, Lilly; Boehringer; Sandoz, Speakers bureau: Abbvie, Pfizer, Roche, Chugai, UCB, BMS, Celgene, MSD, Novartis, Biotest, Janssen, Genzyme, Lilly; Boehringer; Sandoz, Christoph Baerwald Consultant of: CGB received speaker or consulting fees from AbbVie, Paid instructor for: CGB received speaker or consulting fees from AbbVie, Speakers bureau: CGB received speaker or consulting fees from AbbVie, Stephanie Finzel: None declared, Reinhard Voll: None declared, Eugen Feist Consultant of: Novartis, Roche, Sobi, Lilly, Pfizer, Abbvie, BMS, MSD, Sanofi, Speakers bureau: Novartis, Roche, Sobi, Lilly, Pfizer, Abbvie, BMS, MSD, Sanofi, José Antonio P. da Silva Grant/research support from: Pfizer, Abbvie, Consultant of: Pfizer, AbbVie, Roche, Lilly, Novartis, Arnd Doerfler: None declared, Nemanja Damjanov Grant/research support from: from AbbVie, Pfizer, and Roche, Consultant of: AbbVie, Gedeon Richter, Merck, Novartis, Pfizer, and Roche, Speakers bureau: AbbVie, Gedeon Richter, Merck, Novartis, Pfizer, and Roche, Andreas Hess: None declared, Georg Schett Speakers bureau: AbbVie, BMS, Celgene, Janssen, Eli Lilly, Novartis, Roche and UCB DOI: 10.1136/annrheumdis-2020-eular.5249

\section{OP0118 DECIPHERING THE ANTI-PROTEIN-ARGININE DEIMINASE (PAD) RESPONSE IDENTIFIES PAD1 AND PAD6 AS NOVEL AUTOANTIGENS IN RHEUMATOID ARTHRITIS}

L. Martinez-Prat ${ }^{1}$, M. A. Aure ${ }^{2}$, C. Bentow ${ }^{2}$, D. Lucia², M. Lopez-Hoyos ${ }^{3}$, M. Mahler ${ }^{2} .{ }^{1}$ Inova Diagnostics, Research and Development, Barcelona, Spain; ${ }^{2}$ Inova Diagnostics, Inc., Research and Development, San Diego, United States of America; ${ }^{3}$ Marqués de Valdecilla University Hospital, Immunology, Santander, Spain

Background: Protein-arginine deiminase (PAD) 4 enzymes play a central role in the pathogenesis of rheumatoid arthritis (RA) and represents an antigenic target. Among the five known family members (PAD1, PAD2, PAD3, PAD4 and PAD6), only PAD2, PAD3 and PAD4 have been described to have autoantigenic properties. Furtheremore, very little is known on the the isotype usage of these autoantibodies. Understanding the molecular basis of the anti-PAD antibody reponse has the potential to open novel approaches for precision medicine in RA.

Objectives: The objectives of this study were to screen for the presence of antibodies to the five PAD family members and to evaluate the isotype usage of the anti-PAD4 response in RA.

Methods: First, we developed a panel for the detection of anti-PAD IgG based on a particle-based multi-analyte technology (PMAT), that utilized paramagnetic particles coupled with the different human recombinant PAD proteins (PAD1, PAD2, PAD3, PAD4 and PAD6) and anti-human IgG conjugate. This panel was used to test sera from RA patients $(n=33)$ and non-RA controls $(n=36)$. The controls were comprised of apparently healthy individuals $(n=10)$, and patients with infectious diseases $(n=10)$, systemic lupus erythematosus $(n=7)$, systemic sclerosis $(n=9)$ and Sjogren's syndrome $(n=1)$. Next, the PAD4-coupled beads were tested with anti-human $\lg \mathrm{M}$, IgA and IgG conjugates on an extended cohort of RA patients $(n=62)$ and the same non-RA controls.

Results: All five anti-PAD IgG (Figure 1) demonstrated the ability to discriminate between RA patients and controls. At greater than $90 \%$ specificity, antiPAD4 lgG, followed by anti-PAD3 IgG, showed the best diagnostic performance. Significantly higher levels of the five antibodies were observed in RA vs. controls ( $p$-values of $0.0041,<0.0001,0.0014,0.0039$, and 0.0140 for anti-PAD1, 2, 3, 4 and 6 , respectively). Significant correlation was observed between all the antibodies, with the highest between anti-PAD1 and anti-PAD4 (Spearman's $r h o=0.87, p<0.0001$ ) and the lowest between anti-PAD4 and anti-PAD2 (Spearman's $r h o=0.38, p=0.0015$ ) and anti-PAD4 and anti-PAD6 (Spearman's $r h o=0.38$, $p=0.0011$ ). While principal component analysis (PCA) (Figure 2) showed an association between all anti-PAD antibodies, there was further discrimination that displayed closer association between anti-PAD1, 3 and 4 on one hand, and between anti-PAD2 and 6. For the extended testing of anti-PAD4 with IgG, IgA and IgM, all three isotypes were identified in the sera of RA patients. Higher levels of the three isotypes were observed in RA patients with erosive disease when compared with the patients without erosion, but this association was only significant for anti-PAD4 IgA $(p=0.0086)$.

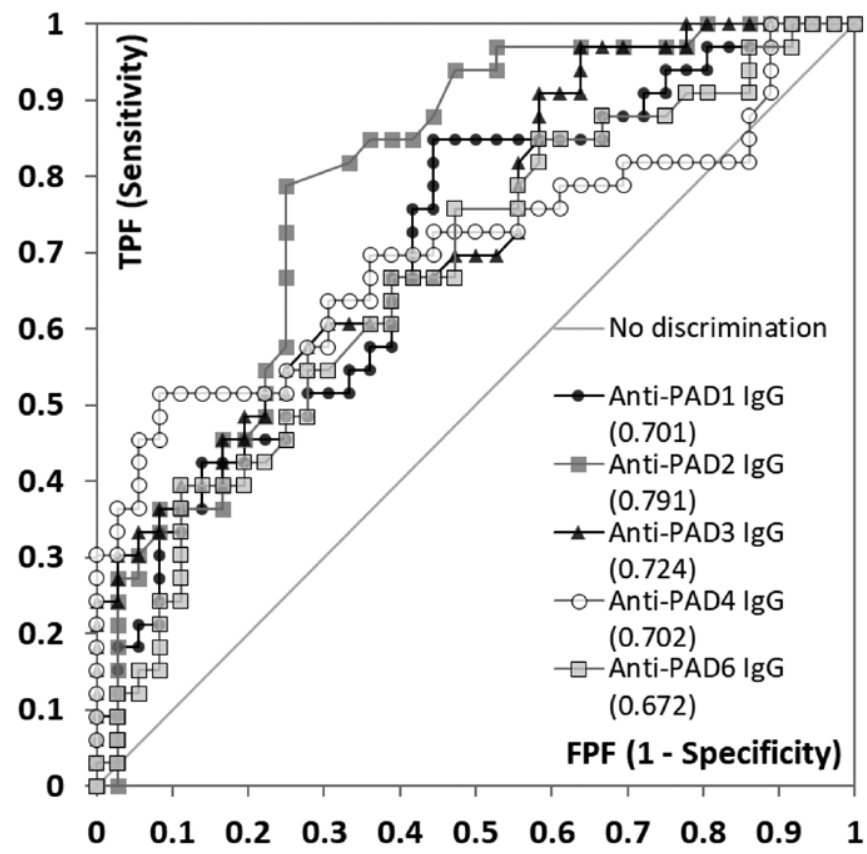

Figure 1. Receiver operating characteristics $(R O C)$ analysis of the discrimination between rheumatoid arthritis (RA) and controls of IgG to protein-arginine deiminase (PAD) 1, PAD2 PAD3, PAD4 and PAD6. The area under the curve (AUC) values are shown in brackets for each biomarker.Abbreviations: TPF: true positive fraction; FPF: false positive fraction

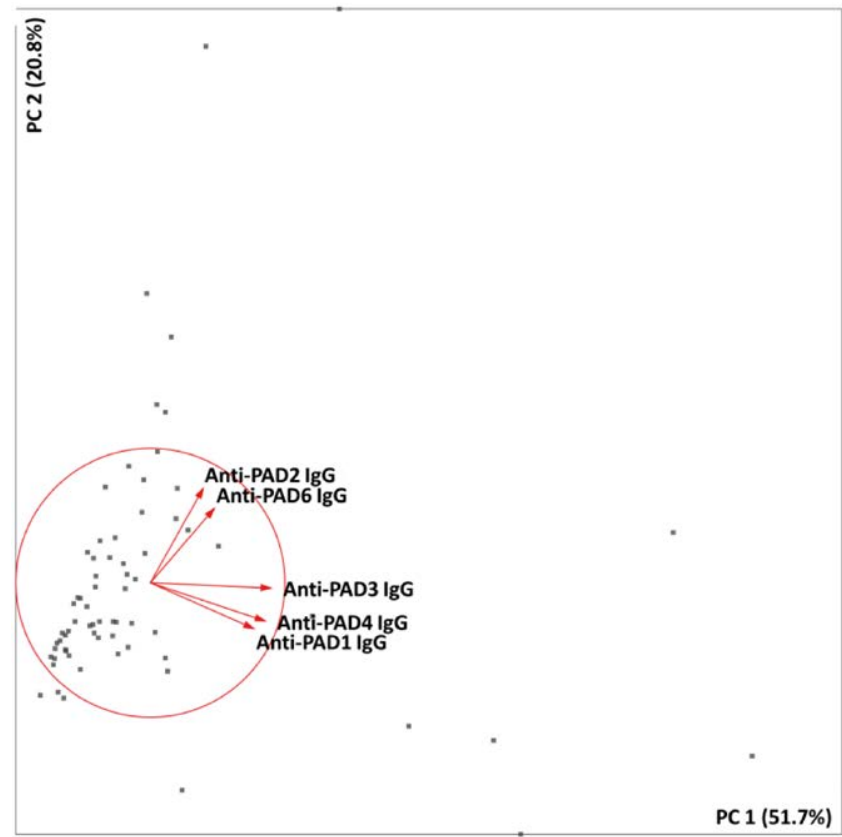

Figure 2. Two dimensional principal component analysis (PCA) plot of the anti-PAD levels in RA patients $(n=33)$ and controls $(n=36)$. Anti-PAD1, 3 and 4 have the main contribution to PC1, which explains $51.7 \%$ of the variance, and anti-PAD2 and 6 to PC2, that represents $20.8 \%$ of it.Abbreviations: PC: principal component 